\title{
High school students' acceptance and use of mobile technology in learning mathematics
}

\author{
Kübra Açıkgüll ${ }^{1}$ · Süleyman Nihat Şad²
}

Received: 2 December 2020 / Accepted: 8 February 2021 / Published online: 27 February 2021

(c) The Author(s), under exclusive licence to Springer Science+Business Media, LLC part of Springer Nature 2021

\begin{abstract}
The purpose of this research is to investigate factors affecting the acceptance and use of mobile technology in learning mathematics based on the Unified Theory of Acceptance and Use of Technology 2 (UTAUT2) model. The study group comprised of 1640 students attending different types of high schools and grade levels. The results of the study revealed both direct and indirect effects of exogenous variables on Behavioral Intention and Use Behavior in mobile technology acceptance of high school students in learning mathematics. It was also found that the theoretical model was confirmed adequately based on the regression coefficients, the significance of the regression coefficients, and the goodness of fit indices obtained from the SEM analysis. The strongest predictors of Behavioral Intention were Hedonic Motivation and Habit, respectively. Exogenous variables of the study together explained $76 \%$ of the variance in Behavioral Intention and $13 \%$ of the variance in Use Behavior.
\end{abstract}

Keywords Technology acceptance $\cdot$ UTAUT2 $\cdot$ Mobile technology $\cdot$ Learning mathematics $\cdot$ Structural equation modeling

\section{Introduction}

Thanks to rapid developments in mobile and wireless technologies, access to information has become easier and cheaper (Wu et al. 2012). In addition, with the advanced technology development and high level of connectivity to the Internet via wireless networks at schools, students and teachers are able to use their

Kübra Açıkgül

kubra.acikgul@gmail.com; kubra.acikgul@inonu.edu.tr

Süleyman Nihat Şad

nihat.sad@inonu.edu.tr

1 Department of Mathematics Education, Faculty of Education, İnonu University, Malatya, Turkey

2 Department of Curriculum and Instruction, Faculty of Education, İnonu University, Malatya, Turkey 
mobile devices including smartphones, tablet computers, and laptops in classrooms for teaching and learning (Wong 2014). These developments have revolutionized the know-how in education (Awadhiya and Miglani 2016) and led to the emergence of the concept of mobile learning (m-learning) (Hamidi and Chavoshi 2018). Mobile learning has been widely accepted as a useful tool in education thanks to the unique features of mobile devices (Christensen and Knezek 2017).

Since content matters in terms of technology use in education (Graham et al. 2009), it has been deemed important to examine mobile learning applications in detail for different subjects such as mathematics, science, and social sciences in order to fully reveal the benefits of mobile learning (Chung et al. 2019). Previous researches have shown that mobile learning has positive effects on cognitive features such as students' math success (e.g., Hung et al. 2014; Kyriakides et al. 2016; Riconscente 2013) and problem-solving skills (Haydon et al. 2012; Saedi et al. 2018). Moreover, the researches have shown that the use of mobile technology while learning mathematics also supports the development of affective outcomes among students including attitude (Riconscente 2013), motivation (Hung et al. 2014; Wijers et al. 2010), self-efficacy (Hung et al. 2014), and interest (Kyriakides et al. 2016). Despite the abovementioned advantages, the implementation of mobile learning is a difficult and complex endeavor (Cheon et al. 2012; Wang et al. 2009). Mobile learning is a method that combines the use of multiple new technologies including online networking, mobile content, and mobile devices, and has a higher level of uncertainty and risk in individuals' perceptions that may lead them to reject or delay acceptance of mobile learning (Kim and Rha 2018). Thus, the acceptance of mobile technologies by learners is considered very important in order to maximize the advantages of mobile learning (Abu-AlAish and Love 2013; Botero et al. 2018; Wang et al. 2009). In order to increase the acceptance of mobile learning, it is necessary to determine and consider the factors that affect learners' acceptance of mobile learning system (Abu-Al-Aish and Love 2013; Arain et al. 2019; Wang et al. 2009). Although mobile devices are increasingly used among students (Nikolopoulou 2018), there are not enough studies on the adoption of mobile technologies (Çukurbaşı et al. 2016; Horzum et al. 2014; Nikolopoulou 2018).

In cooperation with a local communication company, Turkish Ministry of National Education has provided schools in Turkey with internet infrastructure starting from 2003; and with the launch of the FATIH (Movement of Enhancing Opportunities and Improving Technology) project in 2010, teachers and students in high schools were granted tablet computers to a great extent in Turkey (Açıkgül and Şad 2020). These developments imply that high school education in Turkey has experienced m-learning for about a decade now. As a matter of fact, Turkey is among one of the 11 leading countries which have recently achieved state-sponsored integration of ICT investments, in terms of size and number of tablets granted to students (Tamim et al. 2015). However, there are very few studies (Çukurbaşı et al. 2016; Horzum et al. 2014) examining the acceptance levels of students of these and such mobile technologies in Turkey. Therefore, in this study, it was considered important to investigate the factors affecting the mobile technology acceptance of high school students in learning mathematics. 


\section{Literature review}

\subsection{Mobile learning}

M-learning is recognized as one of the most important emerging trends of current educational practices (Nikou and Economides 2017; Wu et al. 2012). It has become increasingly popular due to the low cost of telecommunication facilities and the high quality of mobile devices (Park et al. 2012). With its emergence, the concept of m-learning has attracted the attention of many researchers and various definitions of mobile learning have been made. For example, Crompton (2013 p. 4) defined m-learning as "learning across multiple contexts, through social and content interactions, using personal electronic devices". Crompton and Burke (2018) also stated that mobile learning refers to learning which involves the use of a mobile device. Similarly, many researchers (e.g. Aljuaid et al. 2014; Hamidi and Chavoshi 2018; Park et al. 2012) have defined it as learning via portable tools such as phones, Palms, Windows CE machines and iPods, personal digital assistants (PDAs), audio players, and electronic books, etc., featuring the devices used for mobile learning. Martin and Ertzberger (2013 p.77), on the other hand, defined m-learning as "learning that occurs when learners have access to information anytime and anywhere via mobile technologies to perform authentic activities in the context of their learning", emphasizing its ubiquitous nature.

Since m-learning convey learning out of school, learners have the opportunity to learn anytime and anywhere without the time and place limits (Chung et al. 2019; Hamidi and Chavoshi 2018; Martin and Ertzberger 2013; Wijers et al. 2010). With always accessible mobile devices, learning content can be sent to and recorded by students easily (Hamidi and Chavoshi 2018). It allows learners to collaborate and share ideas (Hamidi and Chavoshi 2018; Wijers et al. 2010). It also supports individualized learning by allowing students to work at their own pace (Cheon et al. 2012). Previous researches have reported that thanks to these advantages m-learning positively affects students' achievement (Hwang and Wu 2014; Martin and Ertzberger 2013), learning motivation (Hwang and Wu 2014; Wijers et al 2010), attitudes (Hwang and Chang 2011; Martin and Ertzberger 2013), communication skills and creativity (Lai and Hwang 2014), and problem-solving skills (Lai and Hwang 2014; Saedi et al. 2018).

\subsection{M-learning in teaching mathematics}

Mobile technologies and applications are also seen as potentially effective pedagogical tools for teaching and learning mathematics (Sollervall et al. 2012). Mobile devices are not limited to traditional equipment and materials found on shelves in math classrooms. Instead, resource diversity increases with portable, accessible, internet-enabled mobile devices, and students are offered access opportunities both at school and outside of school (Attard and Northcote 2012; Borba et al. 2016). Combined with the touch screen feature, the dynamism and visualization features of mobile devices offer students the opportunity to directly interact with mathematical 
events (Larkin and Calder 2016). Students involved in learning mathematics with mobile devices have the opportunity to explore mathematics independently, learn mathematics through cooperation and teamwork, learn mathematics in real-life situations, visualize and research mathematics dynamically, and learn mathematics easily (Baya'a and Daher 2009).

Despite the well-reported advantages of mobile learning in mathematics education, it also has various technical limitations including limited performance, limited processing power, limited memory capacity, short battery life, small screen sizes, small key-in size, reduced input capabilities, slow downloading, and cost (Aljuaid et al. 2014; Baharom and Hussain 2013; Wang et al. 2009). Besides these limitations and challenges, many researchers (e.g. Al-Emran et al. 2018; Awadhiya and Miglani 2016; Wang et al. 2009) pointed out that the success of mobile learning largely depends on learners' acceptance and adoption of mobile learning. The importance emphasized by the researchers on mobile learning has increased the interest in researches on investigating the acceptance of mobile learning by students and educators (Al-Emran et al. 2018; Nikou and Economides 2017).

\subsection{Technology acceptance models and unified theory of acceptance and use of technology}

Recently, many theoretical models have been developed to understand the factors affecting the acceptance and use of technology. The Technology Acceptance Model (TAM), developed by Davis (1989), is the most effective and widely used model to explain individuals' acceptance of information systems (Botero et al. 2018; Šumak and Šroro 2016). TAM provides a parsimonious and theoretic model to examine the factors that lead to the acceptance of information systems (Davis et al. 1989). Although TAM is accepted as the easiest and most robust model, it is stated that information systems give weak and mixed results in acceptance studies (Benbasat and Barki 2007; Šumak and Šorgo 2016). Thus, Venkatesh et al. (2003) proposed a unified model called Unified Theory of Acceptance and Use of Technology (UTAUT), taking into account the conceptual and experimental similarities between eight leading models in the field of information technology acceptance research in order to eliminate the limitations of individual technology acceptance models and to synthesize their strengths. Among the 32 variables and 4 moderator variables in all eight models, 3 variables (Performance Expectancy (PE), Effort Expectancy (EE), Social Influence (SI)), which are the direct determinants of behavioral intention, and 2 variables (Facilitating Conditions (FC) and Behavioral Intention (BI)), which are the direct determinants of use behavior (UB) and 4 moderator variables (age, gender, voluntariness of use, and experience) have been empirically validated through empirical studies (Venkatesh et al. 2003).

The UTAUT model (Venkatesh et al. 2003) was developed in an organizational context for use in technology acceptance researches. Therefore, Venkatesh et al. (2012) aimed to expand the model to the consumer context by adding new components and relationships to the model. The researchers added to the model three new exogenous variables regarding the consumer context: Hedonic Motivation (HM), 
Price Value (PV), and Habit (H). In the model, PE, EE, SI, FC, HM, PV, and H function as direct determinants of behavioral intention (BI); while FC, $\mathrm{H}$, and $\mathrm{BI}$ are used as direct determinants of using behavior (UB), and gender, age, experience variables are included as moderator variables. UTAUT2 model is presented in Fig. 1.

Empirical studies have shown that UTAUT and UTAUT2 models have more explanatory power than other technology acceptance models (Šumak and Šorgo 2016). Therefore, UTAUT models have become frequently used in the field of information technologies since they were developed. For example, UTAUT has been used in different fields including e-Learning systems (Lin et al. 2013), mobile information services in tourism (Fuchs et al. 2012), mobile banking (Zhou et al. 2010), and virtual learning environment adoption (Šumak et al. 2010); while UTAUT2 has been used in mobile banking (Alalwan et al. 2017), mobile shopping (Tak and Panwar 2017), and consumer adoption mechanism for the third-party mobile applications (Vinnik 2017).

One of the subjects where the UTAUT model is frequently used is mobile learning (e.g. Abu-Al-Aish and Love 2013; Alasmari and Zhang 2019; Botero et al. 2018; Cheng et al. 2011; Fagan 2019; Jairak et al. 2009; Sultana 2020; Wang et al. 2009). However, Hew et al. (2015) point out that there are not enough studies which use the UTAUT2 model and focus on mobile applications. Indeed, there are fewer studies in the literature investigating mobile technology acceptance using the UTAUT2 model (Arain et al. 2019; Escobar-Rodríguez et al. 2014; Moorthy et al. 2019;

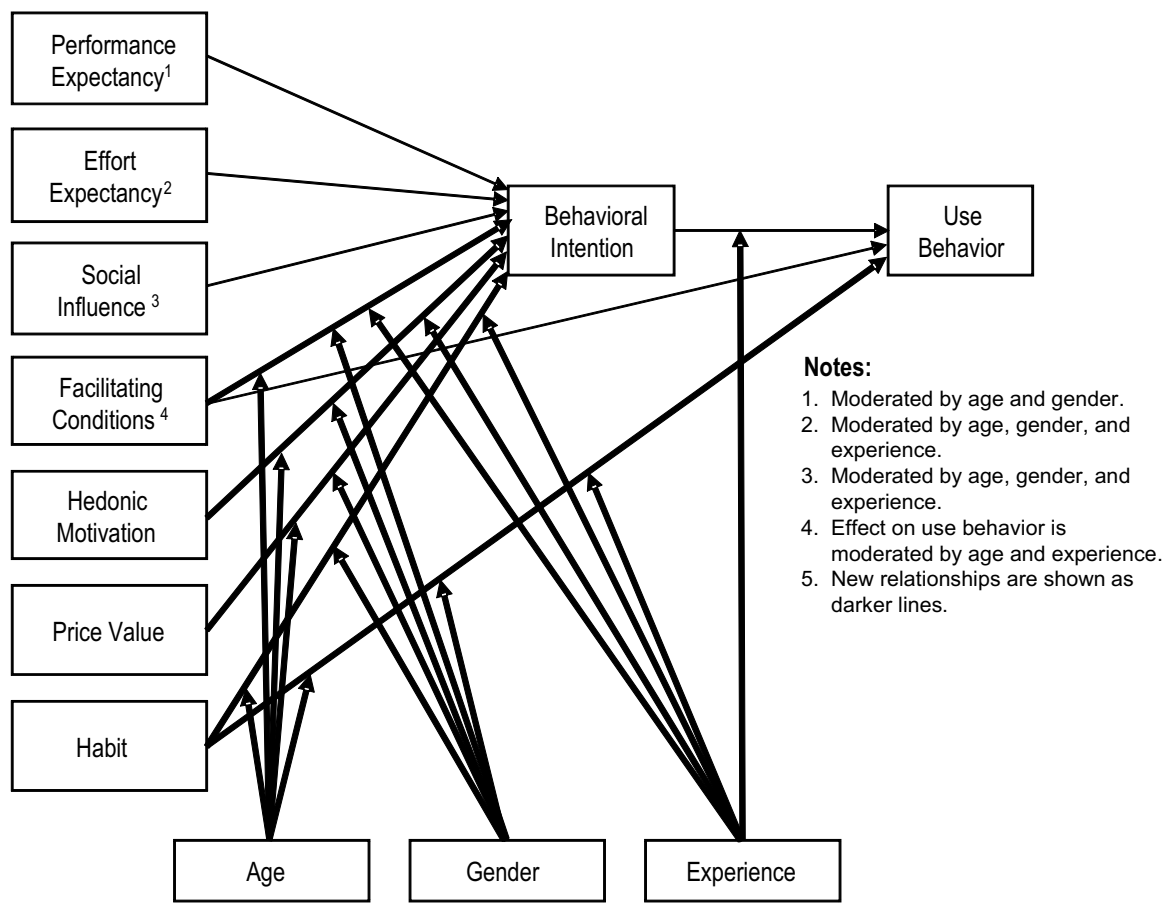

Fig. 1 Components and relations of UTAUT2 model (Venkatesh et al. 2012) 
Nikolopoulou et al. 2020). In this study, the factors affecting high school students' acceptance of mobile technology in mathematics learning were investigated using the UTAUT2 model, since it is the synthesis of the most widely used technology acceptance models, it is one of the most up-to-date technology acceptance models, the model explains a higher variance within the consumer context and it has limited use in mobile learning studies. In the study, the definitions of the components in UTAUT and UTAUT2 models were adapted and used for high school students' use of mobile technology in learning mathematics. Explanations of the components and the study results regarding their effects in the model are presented below:

Behavioral Intention (BI): It is the strength of students' intention to perform a specified behavior using a mobile technology in learning [mathematics] (Fishbein and Ajzen 1975). Previous researches (Botero et al. 2018; Cheng et al. 2011; Nikolopoulou et al. 2020; Sultana 2020) have shown that behavioral intention in the context of mobile learning has a direct effect on use behavior.

Performance Expectancy (PE): It is the degree to which a student believes that using mobile technology will provide benefits in performing [mathematics] activities (Venkatesh et al. 2003, 2012). Many researches (Abu-Al-Aish and Love 2013; Arain et al. 2019; Fagan 2019; Nikolopoulou et al. 2020; Sultana 2020; Wang et al. 2009) suggested that performance expectancy is a significant predictor of behavioral intention within the context of mobile learning.

Effort Expectancy (EE): It is the degree of ease associated with students' use of mobile technology in learning [mathematics] (Venkatesh et al. 2003, 2012). Many researches (Abu-Al-Aish and Love 2013; Jairak et al. 2009; Sultana 2020; Wang et al. 2009) found that effort expectancy is a significant predictor of behavioral intention within the context of mobile learning.

Social Influence (SI): It is the degree to which a student perceives that important others (e.g., friends and family) believe she or he should use the mobile technology in learning [mathematics] (Venkatesh et al. 2003, 2012). Many researches (Abu-Al-Aish and Love 2013; Botero et al. 2018; Cheng et al. 2011; Jairak et al. 2009; Moorthy et al. 2019; Nikolopoulou et al. 2020; Wang et al. 2009) found that social influence has a significant effect on behavioral intention within the context of mobile learning.

Facilitating Conditions (FC): It refers to students' perception of resources or support available to use mobile technology in [mathematics] learning (Venkatesh et al. 2003, 2012). Previous researches found that facilitating condition has a direct significant effect on behavioral intention (Botero et al. 2018; EscobarRodríguez et al. 2014; Jairak et al. 2009) and use behavior (Botero et al. 2018; Nikolopoulou et al. 2020) within the context of mobile learning.

Hedonic Motivation (HM): It refers to the fun or pleasure derived from using a mobile technology in learning [mathematics] (Venkatesh et al. 2012). Previous researches (Arain et al. 2019; Moorthy et al. 2019; Nikolopoulou et al. 2020) showed that that hedonic motivation can be a significant predictor of behavioral intention within the context of mobile learning.

Price Value (PV): It is the students' cognitive trade-off between the perceived benefits of the mobile applications in learning [mathematics] and the monetary 
cost for using them (Venkatesh et al. 2012). Moorthy et al. (2019) found that price value has a direct impact on the behavioral intentions of higher education students in Malaysia within the context of mobile learning.

Habit (H): It refers to the extent to which students tend to perform behaviors using mobile technology automatically in learning [mathematics] (Limayem et al. 2007). There are research results showing that habit has a direct effect on behavioral intention within the context of mobile learning (Arain et al. 2018; Moorthy et al. 2019; Nikolopoulou et al. 2020). Moreover, In the UTAUT2 model, it was determined that habit is a direct predictor of use behavior. (Venkatesh et al. 2012).

\subsection{The current study}

As summarized above mobile technology acceptance is one of the factors affecting the use of mobile technology in education. However, no study has been found on the factors affecting the acceptance and use of mobile technology in learning mathematics. Specifically, in this study, the factors affecting the acceptance and use of mobile technology in mathematics learning of high school students were investigated within the framework of UTAUT2 model.

As explained in literature review, mobile learning acceptance studies have revealed that $\mathrm{PE}, \mathrm{EE}, \mathrm{SI}, \mathrm{FC}, \mathrm{HM}, \mathrm{PV}, \mathrm{H}$ variables are significant predictors of $\mathrm{BI}$, while $\mathrm{FC}, \mathrm{H}$ and $\mathrm{BI}$ variables have direct significant effect on UB. Accordingly, in this study we examined the direct and indirect effects of PE, EE, SI, FC, HM, PV, H variables on $\mathrm{BI}$, and the $\mathrm{BI}, \mathrm{FC}$ and $\mathrm{H}$ variables on use behavior within the context of mobile technology acceptance according to the UTAUT2 model (Venkatesh et al. 2012). On the other hand, although the UTAUT2 model includes the moderator effect of gender, age and experience variables, it has been frequently reported that gender (Alasmari and Zhang 2019; Cheng et al. 2011; Moorthy et al. 2019; Nikolopoulou et al. 2020; Wang et al. 2009), age (Alasmari and Zhang 2019; Cheng et al. 2011; Nikolopoulou et al. 2020) and experience (Alasmari and Zhang 2019; Nikolopoulou et al. 2020) variables do not have a significant moderation effect in mobile learning acceptance studies in the literature. Therefore, the moderator variable effect was not investigated in this study. We tested the following hypotheses using Structural Equation Modeling:

H1: PE has a positive effect on BI to use mobile technology to learn mathematics.

H2: EE has a positive effect on BI to use mobile technology to learn mathematics.

H3: SI has a positive effect on BI to use mobile technology to learn mathematics.

H4: FC has a positive effect on BI to use mobile technology to learn mathematics.

H5: HM has a positive effect on BI to use mobile technology to learn mathematics. 
H6: PV has a positive effect on BI to use mobile technology to learn mathematics.

H7: $\mathrm{H}$ has a positive effect on BI to use mobile technology to learn mathematics. H8: FC has a positive effect on using mobile technology (UB) to learn mathematics.

H9: $\mathrm{H}$ has a positive effect on using mobile technology (UB) to learn mathematics.

H10: BI has a positive effect on using mobile technology (UB) to learn mathematics.

\section{Method}

\subsection{Participants and procedure}

A total of 1640 students attending secondary education in the province of Malatya, a metropolitan city located in the eastern part of Turkey, participated in the study (Age: Mean=15.90, $\mathrm{S}=1.01$, Range=13-19). The information about the participating students and their schools are presented in Table 1.

Before data collection, necessary permissions were obtained from the local authorities. The students were informed about the purpose of the research. We worked with students who volunteered to participate in the study.

Table 1 Students and school characteristics of the participants $(n=1640)$

\begin{tabular}{lll}
\hline & $n$ & $\%$ \\
\hline Gender & & \\
$\quad$ Male & 803 & 49 \\
Female & 837 & 51 \\
Type of high school & & \\
$\quad$ Science & 293 & 17.9 \\
Anatolian & 1235 & 75.3 \\
Private & 112 & 6.8 \\
Grade level & & \\
Grade 9 & 443 & 27 \\
Grade 10 & 669 & 40.8 \\
Grade 11 & 391 & 23.8 \\
Grade 12 & 137 & 8.4 \\
Frequency of using mobile technology in learning mathematics \\
Never & 324 & 19.8 \\
Rarely & 396 & 24.1 \\
Sometimes & 531 & 32.4 \\
Generally & 307 & 18.7 \\
Always & 82 & 5 \\
\hline
\end{tabular}




\subsection{Measures}

Information about participants' gender, age, grade level, type of high school and mobile technology use behaviors were collected with an initial questionnaire form. In order to determine the mobile technology use behavior in learning mathematics, students were asked to indicate their frequency of using mobile technology in learning mathematics by selecting one of the options: "never", "rarely", "sometimes", "generally", and "always". Mobile Technology Acceptance Scale for Learning Mathematics developed by Açıkgül and Şad (2020) was used to measure PE, EE, SI, FC, HM, PV, H, and BI.

\subsubsection{Mobile Technology Acceptance Scale for Learning Mathematics (m-TASLM)}

In their study, Açıkgül and Şad (2020) developed m-TASLM to measure the acceptance levels of high school students in learning mathematics based on the UTAUT2 model developed by Venkatesh et al. (2012). This likert type scale has a 5-point response set ranging between Strongly Disagree and Strongly Agree. Content validity of the scale was proved statistically using LawShe (1975) technique. As a result of the exploratory factor analysis conducted to test the construct validity, a construct was obtained with 36 items under 8 factors that explains $66.068 \%$ of the total variance. The scale included 6 items in PE factor, 3 items in EE factor, 5 items in SI factor, 5 items in FC factor, 4 items in HM factor, 3 items in PV factor, 4 items in $\mathrm{H}$ factor, and 6 items in BI factor. The follow-up confirmatory factor analysis confirmed the 8-factor construct of the scale $(\chi 2 / \mathrm{df}=2.44$; RMSEA $=0.044, \mathrm{RMR}=0.058$, $\mathrm{SRMR}=0.041, \mathrm{CFI}=0.99, \mathrm{GFI}=0.90, \mathrm{AGFI}=0.89, \mathrm{NFI}=0.99, \mathrm{NNFI}=0.99)$.

The reliability of the scale was estimated through test-retest analysis $(r=0.932$, $p=<0.05)$, Cronbach Alfa $(\alpha \geq 0.86)$, CR $(\geq 0.87)$ and AVE $(\geq 0.62)$ coefficients, which yielded favorable results proving the reliability of scores obtained from the scale. As a result, the m-TASLM was found to be a valid and reliable instrument to measure high school students' acceptance levels of mobile technologies in learning mathematics (Açıkgül and Şad 2020). Also, in this study Cronbach Alpha coefficients yielded favorable results proving the reliability of scores: $\mathrm{PE}=0.93$, $\mathrm{EE}=0.90, \mathrm{SI}=0.91, \mathrm{FC}=0.90, \mathrm{HM}=0.92, \mathrm{H}=0.89, \mathrm{PV}=0.89, \mathrm{BI}=.93$, and total $=0.97$.

\subsection{Data-analysis plan}

Structural equation modeling (SEM) was carried out using the AMOS software program to test the direct and indirect relationships (depicted in Fig. 1) between the variables PE, EE, SI, FC, HM, PV, H, BI, and UB. A two-stage approach was used in SEM analysis (Kline 2011). First, the relation of observed structures with latent structures was examined by testing the measurement model. Second, the relationships between latent structures were examined by testing the structural model. While interpreting SEM results, the goodness of fit indices were regarded acceptable when 
$\chi 2$ / $\mathrm{df} \leq 5$; GFI, AGFI, CFI, NFI, and TLI $\geq 0.90$; SRMR, RMSEA $\leq 0.80$, and they were considered perfect when $\chi 2 / \mathrm{df} \leq 3$; GFI, AGFI, CFI, NFI and TLI $\geq 0.95$; SRMR, RMSEA $\leq 0.60$ (Brown 2006; Hair et al. 2014; Tabachnick and Fidell 2013). Moreover, to provide evidence whether the mediation effect of BI between exogenous variables (PE, EE, SI, FC, HM, PV, H) and UB is significant, we used the bootstrapping method, which is a powerful and useful tool commonly used to test the statistical significance of indirect influence in mediation models (Koopman et al. 2015).

Finally, to test whether the measurement is susceptible to common method variance (CMV) Harman's single factor test was used and the one-dimensional structure of the mobile technology acceptance scale in learning mathematics was tested with CFA (Podsakoff et al. 2003 p.889). As a result of the analysis, it was seen that the one-dimensional model was not confirmed $(\chi 2 / \mathrm{df}=14.07$; RMSEA $=0.185$, $\mathrm{RMR}=0.18, \quad \mathrm{SRMR}=0.10, \mathrm{CFI}=0.92, \quad \mathrm{GFI}=0.45, \quad \mathrm{AGFI}=0.38, \quad \mathrm{NFI}=0.91$, $\mathrm{NNFI}=0.92$ ), which means the measure does not suffer from common method variance.

\section{Results}

Correlations between variables and descriptive statistics are presented in Table 2.

The skewness and kurtosis values in Table 2 are in the range of \pm 1 , which indicates that the distribution of the data of the variables is close to normal (Hair et al. 2014). In addition, all variables were found to be significantly correlated with each other in positive direction.

\subsection{Measurement model}

In the measurement model, there are 8 latent variables PE, EE, SI, FC, HM, PV, H, $\mathrm{BI}$ and 36 observable variables. Relationships between latent variables and observable variables were investigated through CFA, which revealed that all path coefficients are significant and standardized factor loads range between 0.815 and 0.854 in PE factor, between 0.840 and 0.867 in EE factor, between 0.716 and 0.878 in SI factor, between 0.641 and 0.893 in FC factor, between 0.822 and 0.901 in HM factor, between 0.816 to 0.897 in PV dimension, between 0.782 and 0.846 in $\mathrm{H}$ dimension, and between 0.794 and 0.861 in BI factor. The adequate goodness of fit indices $(\chi 2 /$ $\mathrm{df}=2794.131 / 563=4.963, \mathrm{p}=0.000 ; \mathrm{SRMR}=0.047 ; \mathrm{GFI}=0.911 ; \mathrm{AGFI}=0.895$; $\mathrm{CFI}=0.956$; NFI $=0.945 ; \mathrm{TLI}=0.950 ; \mathrm{RMSEA}=0.049$ ) confirmed the accuracy of measurement model.

\subsection{Structural model}

In the second stage of SEM, the hypothesized relationships between latent variables in Fig. 2 were tested. Before testing the model, univariate and multivariate normality assumptions were checked. It was determined that the $\mathrm{z}$ scores calculated 


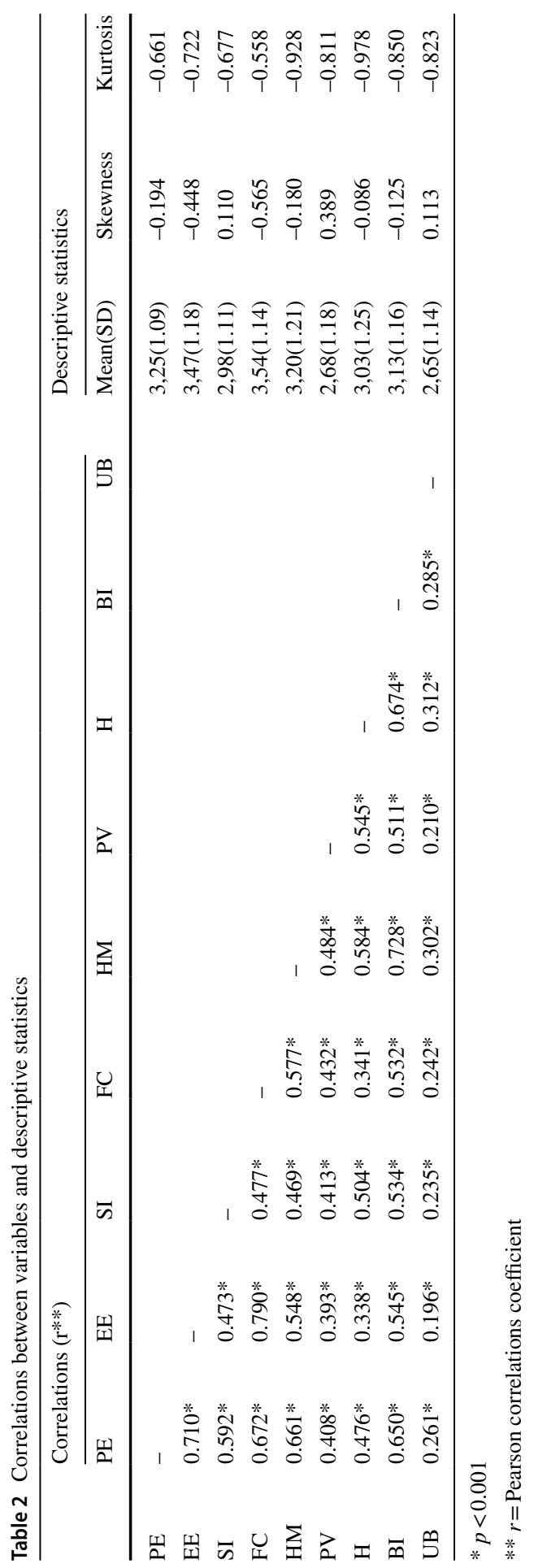


Fig. 2 Research model

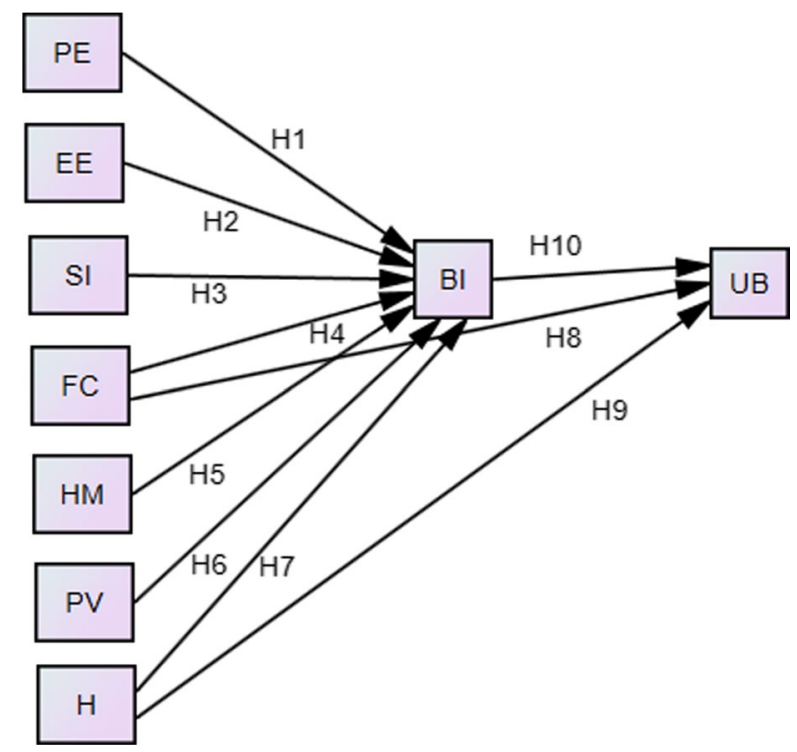

to detect the univariate outliers were between \pm 3.29 , suggesting no univariate outliers (Tabachnick and Fidell 2013). Mahalanobis distance values were calculated to find multivariate outliers $(p<0.001)$ and a total of 227 cases were excluded from the analysis (Tabachnick and Fidell 2013). Moreover, the multivariate normality analysis yielded a kurtosis value of 3.289 with a critical ration of 4.393), which is favorable since a critical ration less then 5 is acceptable for multivariate normality (Bentler 2006). In testing the structural model, the Maximum Likelihood estimation method

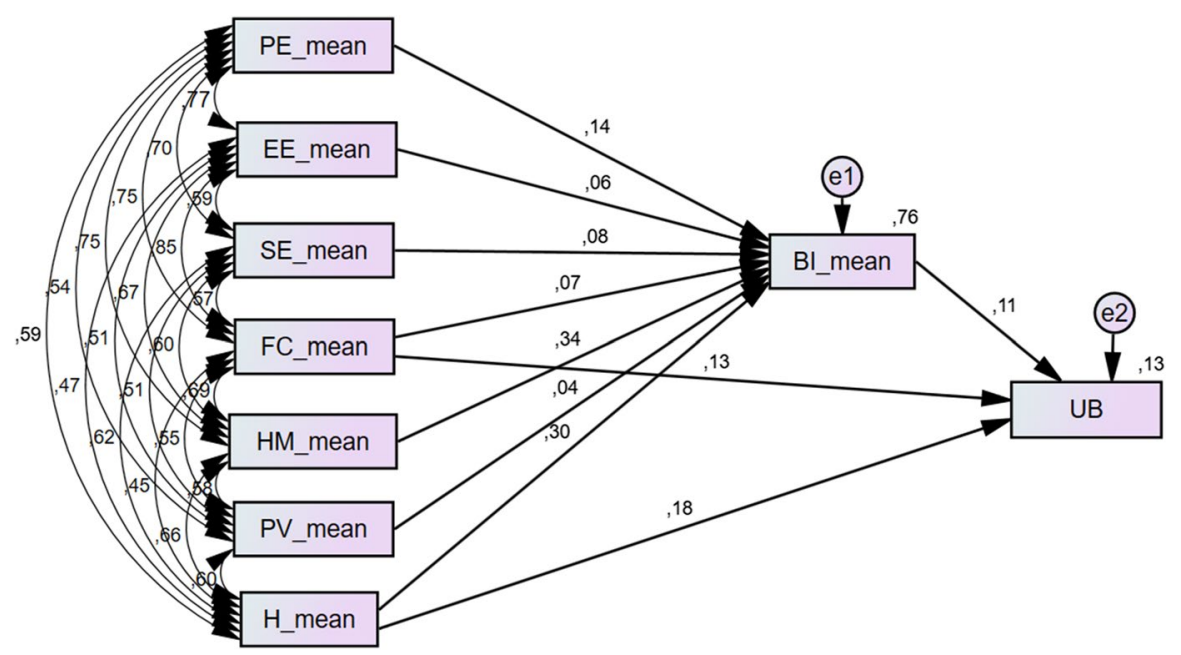

Fig. 3 Path diagram of the model, standardized path coefficients, and explained variance 
was used, as it is frequently used in cases where the assumption of multiple normality is satisfied (Kline 2011). Figure 3 shows the tested and validated structural model, and Table 3 shows the values for the regression coefficients and the significance of the regression coefficients.

Table 3 shows that all paths are significant $(p<0.05)$. Also, perfect goodness of fit indices suggest that the research model fits well $(\chi 2 / \mathrm{df}=2.197$, RMSEA $=0.029$, $\mathrm{SRMR}=0.006, \mathrm{GFI}=0.998, \mathrm{AGFI}=0.985, \mathrm{CFI}=0.999, \mathrm{NFI}=0.999, \mathrm{TLI}=0.996$ ).

In Fig. 3, it is seen that the main indigenous variable is UB and other variables affect UB directly and indirectly. According to the confirmed model, PE $(\beta=0.14$; $\mathrm{t}=5.327 ; p<0.05), \mathrm{EE}(\beta=0.06 ; \mathrm{t}=2.410 ; p<0.05)$, SI $(\beta=0.08 ; \mathrm{t}=4.064 ;$ $p<0.05)$, FC $(\beta=0.07 ; \mathrm{t}=2,665 ; p<0.05) ; \mathrm{HM}(\beta=0.34 ; \mathrm{t}=14,991 ; p<0.05)$, PV $(\beta=0.04 ; \mathrm{t}=2,074 ; p<0.05)$, and $\mathrm{H}(\beta=0.30 ; \mathrm{t}=15,207 ; p<0.05)$ have statistically significant positive and direct effects on BI. As it is seen in Fig. 3, these variables altogether account for the $76 \%$ of the total variance in BI. This finding shows that variables have a large impact on BI (Cohen 1988). It was also found that $\mathrm{FC}(\beta=0.13 ; \mathrm{t}=4.019 ; p<0.05) ; \mathrm{H}(\beta=0.18 ; \mathrm{t}=4.814 ; p<0.05)$, and $\mathrm{BI}(\beta=0.11$; $\mathrm{t}=2.439 ; p<0.05)$ have statistically significant positive and direct effects on UB.

Regarding the mediating roles in the model, BI was found to have a mediator role between PE, EE, SI, FC, HM, PV, H and UB. Although the paths between PE, $\mathrm{EE}, \mathrm{SI}, \mathrm{FC}, \mathrm{HM}, \mathrm{PV}, \mathrm{H}$ variables and the $\mathrm{BI}$ variable and between the $\mathrm{BI}$ variable and the UB variable are statistically significant, the Bootstrapping Analysis was performed to determine whether the mediation role was statistically significant. 5,000 bootstraps were performed and the bootstrap coefficient and 95\% significance level confidence intervals were created in AMOS (Hayes 2018). The results of the Boostraping analysis are shown in Table 4.

As seen in the Table 4, the confidence intervals for PE, EE, SI, FC, HM, and $\mathrm{H}$ variables do not include zero, and indirect effects are statistically significant $(p<0.05)$. On the other hand, the indirect effect was not statistically significant for $\mathrm{PV}$, since the confidence intervals calculated for the indirect effect of the PV variable on UB included 0 . Accordingly, it can be said that the BI variable has a significant mediating role between the variables PE, EE, SI, FC, HM, H, and the UB

Table 3 Regression coefficients for the tested model and values for the significance of regression coefficients

\begin{tabular}{llllrl}
\hline Intercorrelations & $\mathrm{B}$ & $\beta$ & $\mathrm{Se}$ & $\mathrm{CR}(\mathrm{t})$ & $p$ \\
\hline $\mathrm{BI}<---\mathrm{PE}$ & .147 & .136 & .028 & 5.327 & $* * *$ \\
$\mathrm{BI}<---\mathrm{EE}$ & .062 & .063 & .026 & 2.410 & $.016^{*}$ \\
$\mathrm{BI}<---\mathrm{SI}$ & .084 & .080 & .021 & 4.064 & $* * *$ \\
$\mathrm{BI}<---\mathrm{FC}$ & .071 & .071 & .027 & 2.665 & .008 \\
$\mathrm{BI}<---\mathrm{HM}$ & .330 & .341 & .022 & 14.991 & $* * *$ \\
$\mathrm{BI}<---\mathrm{PV}$ & .034 & .037 & .016 & 2.074 & $.038^{*}$ \\
$\mathrm{BI}<---\mathrm{H}$ & .291 & .301 & .019 & 15.207 & $* * *$ \\
$\mathrm{UB}<---\mathrm{FC}$ & .135 & .134 & .033 & 4.019 & $* * *$ \\
$\mathrm{UB}<---\mathrm{H}$ & .172 & .178 & .036 & 4.814 & $* * *$ \\
$\mathrm{UB}<---\mathrm{BI}$ & .108 & .108 & .044 & 2.439 & $.015 *$ \\
\hline
\end{tabular}

$\chi 2=10.987 ; \mathrm{df}=5(* p<0.05 ; * * * p=0.000)$ 
Table 4 Standardized direct, indirect and total effects after boostrapping

\begin{tabular}{|c|c|c|c|c|c|c|}
\hline \multirow[t]{2}{*}{ Effect } & \multicolumn{3}{|l|}{ BI } & \multicolumn{3}{|l|}{ UB } \\
\hline & Direct & Indirect & Total & Direct & Indirect(CI) & Total \\
\hline PE & 0.136 & - & 0.136 & - & $0.015 *(0.003-0.030)$ & 0.015 \\
\hline EE & 0.063 & - & 0.063 & - & $0.007 *(0.001-0.016)$ & 0.007 \\
\hline SI & 0.080 & - & 0.080 & - & $0.009 *(0.002-0.018)$ & 0.009 \\
\hline $\mathrm{FC}$ & 0.071 & - & 0.071 & 0.134 & $0.008 *(0.001-0.018)$ & 0.142 \\
\hline HM & 0.341 & - & 0.341 & - & $0.037 *(0.009-0.067)$ & 0.037 \\
\hline PV & 0.037 & - & 0.037 & - & $0.004(0.000-0.011)$ & 0.004 \\
\hline $\mathrm{H}$ & 0.301 & - & 0.301 & 0.178 & $0.032 *(0.007-0.059)$ & 0.210 \\
\hline $\mathrm{BI}$ & - & - & - & 0.108 & - & 0.108 \\
\hline
\end{tabular}

CI Confidence Interval (\%95); ${ }^{*} p<0.05$

variable, but it is not a significant mediator between the PV variable and the UB variable. As a result, about $13 \%$ of the variance in the UB variable is explained indirectly by $\mathrm{PE}, \mathrm{EE}, \mathrm{SI}, \mathrm{HM}$ variables, both directly and indirectly by $\mathrm{FC}$ and $\mathrm{H}$ variables, and directly by BI variable (see Fig. 3). This finding may suggest that variables in the UTAUT2 model together have a moderate effect on UB (Cohen 1988).

\section{Discussion}

This research has proposed a model to explore the effect of the high school students' acceptance of mobile technology in learning mathematics on their use behavior based on the UTAUT2 model. As a result, all hypothesized effects in the model were proved as supported by the previous research findings. Below these findings were discussed in the light of relevant literature.

The significant effect of performance expectancy on BI shows that as students perceive using mobile technologies promises an increase in their performance in mathematics, they have stronger intentions to use mobile technologies in learning mathematics. Contrary to this finding some previous researches (Botero et al. 2018; Cheng et al. 2011; Jairak et al. 2009; Moorthy et al. 2019) reported that PE has no significant effect on $\mathrm{BI}$, whereas many studies have revealed the positive effect of PE on BI in the context of mobile learning (Abu-Al-Aish and Love 2013; Arain et al. 2019; Fagan 2019; Nikolopoulou et al. 2020; Sultana 2020; Wang et al. 2009).

Next, it was found that EE is a significant positive predictor of BI. This finding indicates that students expect the mobile technologies to be easy and should not require much effort in learning mathematics. This result supports the results of the previous studies which reported that EE has a significant effect on BI (Abu-Al-Aish and Love 2013; Jairak et al. 2009; Sultana 2020; Wang et al. 2009). On the other hand, there are many studies in the literature that indicate that EE has no significant effect on BI (Alasmari and Zhang 2019; Arain et al. 2018, 2019; Botero et al. 2018; Cheng et al. 2011; Nikolopoulou et al. 2020; Moorthy et al. 2019). These conflicting 
results may be due to research participants' skills and experiences of using mobile technologies in general or particularly in learning contexts. It is believed that as individuals' skills and experiences to use mobile technologies increase, the effect of effort expectation on behavioral intention may decrease as they can easily use mobile technologies.

In this study, a significant relationship was found between SI and BI. This finding shows that the social milieu surrounding the learners (e.g. peers, teachers, and families etc.) have an impact on their intention of using mobile technology in learning mathematics. Similarly, in many studies, the positive effect of social influence on behavioral intention in the context of mobile learning has been reported (AbuAl-Aish and Love 2013; Botero et al. 2018; Cheng et al. 2011; Jairak et al. 2009; Moorthy et al. 2019; Nikolopoulou et al. 2020; Wang et al. 2009). Contrary to these studies, there are studies which found no predictive relationship between SI and BI (Alasmari and Zhang 2019; Arain et al. 2018, 2019; Fagan 2019; Sultana 2020).

Another finding of the study is the significant predictive impact of FC on BI. It can be said that when students perceive their knowledge, skills and resources as favorable to learn mathematics, their intention to use mobile technology to learn mathematics is also enhanced. Some previous research agrees with this finding, revealing a significant relationship between FC and BI (Arain et al. 2018; Botero et al. 2018; Escobar-Rodríguez et al. 2014; Jairak et al. 2009). On the other hand, there are studies that do not detect a significant predictive relationship between FC and BI (Alasmari and Zhang, 2019; Arain et al. 2019; Moorthy et al. 2019; Nikolopoulou et al. 2020; Sultana 2020).

The research finding regarding the positive effect of $\mathrm{HM}$ on $\mathrm{BI}$ indicates that as the pleasure/joy students get from using mobile technology in learning mathematics increases, their intention to use these technologies also increases. This finding is consistent with the results of the studies in the literature (Arain et al. 2018, 2019; Moorthy et al. 2019; Nikolopoulou et al. 2020). On the other hand, in a study on factors influencing student acceptance of mobile learning in higher education, Fagan (2019) reported that HM has no significant effect on intention.

Another finding of this research is the significant effect of PV on BI, which suggests that mobile technologies (mostly state founded Tablet PCs in this case) used in mathematics learning and the low cost of internet connection have a positive effect on behavioral intention. Similarly, Moorthy et al. (2019) found the significant effect of PV on behavioral intention. On the contrary, in their study of mobile phone acceptance of university students studying in Greece, Nikolopoulou et al. (2020) found that price value does not have a significant effect on intention. Considering that recently Covid-19 has led to higher demands for laptop and mobile devices around the world, Price Value (PV) might have become a more relevant and imperative factor. In Turkey, after Covid-19 forced schools to turn to distance education, the Ministry of Education immediately began supplying free tablet PCs to students with financial difficulties. Also, major national service supplier communication companies granted all customers 8 gigabytes of free internet quota to access to the national learning management system called EBA (Educational Information Network). Thus, Price Value might still have a positive effect on their behavioral intention. However, for those who had to make 
extra expenses for one or more (considering many siblings) mobile devices, behavioral intention or use behavior might not be a matter of voluntary action, but an obligation imposed during the Covid-19 period. Thus, the importance of Price Value can be more objectively evaluated after the Covid-19 period, when most classes turn to face-to-face again.

This research also found the predictive positive effect of $\mathrm{H}$ on $\mathrm{BI}$, which suggests that as the frequency/priority of using mobile technology increases so as to become a habit, the intention to use mobile technology in learning mathematics is positively affected. Similarly, Arain et al. (2018), Moorthy et al. (2019), and Nikolopoulou et al. (2020) reported the positive effect of habit on intention, whereas Fagan (2019) found no predictive relationship between these variables.

Exogenous variables of the study together explained $76 \%$ of the variance in BI. This finding shows that the effect of exogenous variables on BI is great (Cohen 1988). It is also found that the strongest predictors of BI are $\mathrm{HM}$ and $\mathrm{H}$, respectively. Similarly, Moorthy et al. (2019) showed that the strongest predictors of BI were H and HM. Also, Arain et al. (2019) and Nikolopoulou et al. (2020) determined that habit is the strongest predictor of behavioral intention. This finding indicates that a student with a high hedonic motivation and who has developed a habit of using mobile technology is more likely to accept the use of mobile technology in mathematics learning than a student with a lower hedonic motivation and mobile technology usage habit. These findings stress the importance of designing mobile technology applications to encourage students' hedonic motivation and mobile technology use habits in learning mathematics.

The finding about the direct predictive value of $\mathrm{H}, \mathrm{FC}$, and $\mathrm{BI}$, in the order of strength, on the reported frequency of using mobile technologies in learning mathematics is consistent with the previous research findings (for FC see Botero et al. 2018; Nikolopoulou et al. 2020; Venkatesh et al. 2012; for H see Venkatesh et al. 2012; and for BI see Botero et al. 2018; Cheng et al. 2011; Nikolopoulou et al. 2020; Sultana 2020; Venkatesh et al. 2012).

Another finding of this research is that the exogenous variables (e.g. PE, EE, SI, FC, HM, H, and BI) explain only $13 \%$ of the variance in use behavior through direct and indirect effects. This finding indicates a moderate effect (Cohen 1988). Venkatesh et al. (2012) reported that the UTAUT2 model explained $74 \%$ of the variance in behavioral intention and $52 \%$ of the variance in use behavior. In this study, however, while the result about behavioral intention (76\%) was found consistent with the original model, the variance explaination percentage for use behavior (13\%) was lower than expected. The low variance explaination rate in mobile technology usage behavior may have resulted from the low frequency of actual use of mobile technologies in mathematics learning as reported in Table 1 .

As a result, the results of this study and many other studies on mobile technology acceptance revealed the positive effects of PE, EE, SI, FC, HM, PV and $\mathrm{H}$ perceptions on mobile technology acceptance and use among students. If favorable perceptions of $\mathrm{PE}, \mathrm{EE}, \mathrm{SI}, \mathrm{FC}, \mathrm{HM}, \mathrm{PV}$ and $\mathrm{H}$ can positively affect the acceptance and use of mobile technology, it should be ensured that the 
expectations of the students are met with mobile learning environments designed by considering these factors.

\section{Limitations and future directions}

Participants of this research is limited with high school students who were enrolled in public schools in a province in the east of Turkey and who volunteered to participate in the study. Thus, despite the inclusion of students from different school types (Science, Anatolian and Private High School), the results may not be easily generalized to students in other schools or classes. Also, considering that the predictors in the model account for only $13 \%$ of the UB and about $20 \%$ of the sample reported they never use mobile technology to learn Mathematics, the result might not reflect samples with extensive usage of mobile technologies in learning Mathematics. In this study, students' mobile technology acceptance and use levels were measured based on their perceptions. Venkatesh et al. (2003) stated that as individuals gain experience, their perceptions may change. This study is cross-sectional, measuring the perceptions at one given point in time across a sample population. Repeated measurement studies can provide a better understanding of the relationships between variables and the consequences of any changes in students' perceptions over time. Furthermore, in this study, students' levels of accepting mobile technology in learning mathematics were examined. Factors affecting the acceptance levels of students for different fields (science, social sciences) can be investigated comparatively in future researches.

\section{Conclusion}

This is a pioneering study to examine high school students' levels of acceptance and use of mobile technology in learning mathematics in Turkey. It is also unique in using UTAUT2 models for the adoption of mobile technology in maths learning. As a result of SEM analysis in the research, all of the research hypotheses (H1-H10) were accepted. The results of this study reveal both direct and indirect effects of PE, EE, SI, FC, HM, PV, and $\mathrm{H}$ variables on $\mathrm{BI}$ and $\mathrm{UB}$ in mobile technology acceptance of high school students in learning mathematics. In the study, it was found that the theoretical model was confirmed adequately based on the regression coefficients, the significance of the regression coefficients, and the goodness of fit values obtained from the SEM analysis. The important results of the study are as follows: (a) PE, EE, SI, FC, HM, PV, and $\mathrm{H}$ variables have significant positive direct effects on $\mathrm{BI}$. (b) The variables $\mathrm{FC}, \mathrm{H}$, and $\mathrm{BI}$ have significant positive direct effects on UB. (c) PE, EE, SI, FC, HM, and H variables have significant positive indirect effects on the UB variable, and BI play a significant mediator role on these effects. (d) PV does not have a statistically significant indirect effect on the UB variable, over the mediator role of the BI variable. Our results provide the basis for research on mobile technology adoption in 
mathematics learning and expand this literature on UTAUT2. It will also contribute to the development of application environments that will enable practitioners to accept and use mobile technology in mathematics learning.

\section{References}

Açıkgül, K., \& Şad, S. N. (2020). Mobile technology acceptance scale for learning mathematics: Development, validity, and reliability studies. The International Review of Research in Open and Distributed Learning, 21(4), 161-180. https://doi.org/10.19173/irrodl.v21i4.4834.

Abu-Al-Aish, A., \& Love, S. (2013). Factors influencing students' acceptance of m-learning: An investigation in higher education. International Review of Research in Open and Distributed Learning, 14(5), 82-107. https://doi.org/10.19173/irrodl.v14i5.1631.

Al-Emran, M., Mezhuyev, V., \& Kamaludin, A. (2018). Technology Acceptance Model in Mlearning context: A systematic review. Computers \& Education, 125, 389-412. https://doi.org/10.1016/j. compedu.2018.06.008.

Alalwan, A. A., Dwivedi, Y. K., \& Rana, N. P. (2017). Factors influencing adoption of mobile banking by Jordanian bank customers: Extending UTAUT2 with trust. International Journal of Information Management, 37(3), 99-110. https://doi.org/10.1016/j.ijinfomgt.2017.01.002.

Alasmari, T., \& Zhang, K. (2019). Mobile learning technology acceptance in Saudi Arabian higher education: An extended framework and a mixed-method study. Education and Information Technologies, 24(3), 2127-2144. https://doi.org/10.1007/s10639-01909865-8.

Aljuaid, N. M. F., Alzahrani, M. A. R., \& Islam, A. Y. M. (2014). Assessing mobile learning readiness in Saudi Arabia higher education: An empirical study. Malaysian Online Journal of Educational Technology, 2(2), 1-14. Retrieved 21 January 2019 from https://files.eric.ed.gov/fulltext/EJ1086443.pdf.

Arain, A. A., Hussain, Z., Vighio, M. S., \& Rizvi, W. H. (2018). Factors influencing acceptance of Mobile learning by higher education students in Pakistan. Sindh University Research Journal SURJ (Science Series), 50(01), 141-146. https://doi.org/10.26692/sujo/2018.1.0025.

Arain, A. A., Hussain, Z., Rizvi, W. H., \& Vighio, M. S. (2019). Extending UTAUT2 toward acceptance of mobile learning in the context of higher education. Universal Access in the Information Society, 18(3), 659-673. https://doi.org/10.1007/s10209-019-00685-8.

Attard, C., \& Northcote, M. (2012). Mathematics on the move: Using mobile technologies to support student learning (Part 2). Australian Primary Mathematics Classroom, 17(1), 29-32. Retrieved 21 May 2019 from https://files.eric.ed.gov/fulltext/EJ978132.pdf.

Awadhiya, A. K., \& Miglani, A. (2016). Mobile learning: Challenges for teachers of Indian open universities. Journal of Learning for Development-JL4D, 3(2), 35-46. Retrieved 03 February 2018 from https://j14d.org/index.php/ej14d/article/view/145/147.

Baharom, S., \& Hussain, R. M. R. (2013). An exploration of the mobile learning environment to support teacher training. In M. A. Embi \& N. M. Nordin (Eds.), Mobile learning: Malaysian initiatives \& research findings (pp. 103-110). Bangi: Centre For Academic Advancement, Universiti Kebangsaan Malaysia.

Baya'a, N., \& Daher, W. (2009). Students' perceptions of mathematics learning using mobile phones. In Proceedings of the international conference on mobile and computer aided learning (IMCL, 22-924 April (Vol. 4, pp. 1-9), Amman.

Benbasat, I., \& Barki, H. (2007). Quo vadis TAM? Journal of the association for information systems, 8(4), 211-218. https://doi.org/10.17705/1jais.00126.

Bentler, P. M. (2006). EQS 6 Structural equations program manual. Encino, CA: Multivariate Software, INC.

Borba, M. C., Askar, P., Engelbrecht, J., Gadanidis, G., Llinares, S., \& Aguilar, M. S. (2016). Blended learning, e-learning and mobile learning in mathematics education. ZDM, 48(5), 589-610. https:// doi.org/10.1007/s11858-016-0798-4.

Botero, G. G., Questier, F., Cincinnato, S., He, T., \& Zhu, C. (2018). Acceptance and usage of mobile assisted language learning by higher education students. Journal of Computing in Higher Education, 30(3), 426-451. https://doi.org/10.1007/s12528-018-9177-1.

Brown, T. A. (2006). Confirmatory factor analysis for applied research. New York: Guilford Press. 
Cheng, Y. S., Yu, T. F., Huang, C. F., Yu, C., \& Yu, C. C. (2011). The comparison of three major occupations for user acceptance of information technology: Applying the UTAUT model. IBusiness, 3, 147-158. https://doi.org/10.4236/ib.2011.32021.

Cheon, J., Lee, S., Crooks, S. M., \& Song, J. (2012). An investigation of mobile learning readiness in higher education based on the theory of planned behavior. Computers \& education, 59(3), 10541064. https://doi.org/10.1016/j.compedu.2012.04.015.

Christensen, R., \& Knezek, G. (2017). Validating a mobile learning readiness survey: Assessing teachers' dispositions toward adoption. Journal of Digital Learning in Teacher Education, 33(4), 148-159. https://doi.org/10.1080/21532974.2017.1347536.

Chung, C. J., Hwang, G. J., \& Lai, C. L. (2019). A review of experimental mobile learning research in 2010-2016 based on the activity theory framework. Computers \& Education, 129, 1-13. https://doi. org/10.1016/j.compedu.2018.10.010.

Cohen, J. (1988). Statistical power analysis for the behavioral sciences (2nd ed.). Hillsdale: Erlbaum.

Crompton, H. (2013). A historical overview of mobile learning: Toward learner-centered education. In Z. L. Berge \& L. Y. Muilenburg (Eds.), Handbook of mobile learning (pp. 3-14). New York: Routledge.

Crompton, H., \& Burke, D. (2018). The use of mobile learning in higher education: A systematic review. Computers \& Education, 123, 53-64. https://doi.org/10.1016/j.compedu.2018.04.007.

Çukurbaşı, B., İsbulan, O., \& Kıyıcı, M. (2016). Acceptance of educational use of tablet computers: A critical view of the FATIH Project. Education and Science, 41(188), 67-82. https://doi.org/10.15390 /EB.2016.6621.

Davis, F. D. (1989). Perceived usefulness, perceived ease of use, and user acceptance of information technology. MIS Quarterly, 13(3), 319-340. https://doi.org/10.2307/249008.

Davis, F. D., Bagozzi, R. P., \& Warshaw, P. R. (1989). User acceptance of computer technology: A comparison of two theoretical models. Management Science, 35(8), 982-1003. https://doi.org/10.1287/ mnsc.35.8.982.

Escobar-Rodríguez, T., Carvajal-Trujillo, E., \& Monge-Lozano, P. (2014). Factors that influence the perceived advantages and relevance of Facebook as a learning tool: An extension of the UTAUT. Australasian Journal of Educational Technology, 30(2), 136-151. https://doi.org/10.14742/ajet.585.

Fagan, M. H. (2019). Factors influencing student acceptance of mobile learning in higher education. Computers in the Schools, 36(2), 105-121. https://doi.org/10.1080/07380569.2019.1603051.

Fishbein, M., \& Ajzen, I. (1975). Belief, attitude, intention and behaviour: An introduction to theory and research. Reading: Addison-Wesley.

Fuchs, M., Höpken, W., \& Rasinger, J. (2012). Behavioral intention to use mobile information services in tourism: The case of the tourist guide Dolomitisuperski. Mobi. Information Technology \& Tourism, 13(4), 285-307. https://doi.org/10.3727/109830512X13364362859858.

Graham, C. R., Burgoyne, N., Cantrell, P., Smith, L., \& St. Clair, L. and Harris, R. . (2009). TPACK development in science teaching: Measuring the TPACK confidence of inservice science teachers. TechTrends, Special Issue on TPACK, 53(5), 70-79. https://doi.org/10.1007/s11528009-0328-0.

Hair, J. F., Jr., Black, W. C., Babin, B. J., Anderson, R. E., \& Tatham, R. L. (2014). Multivariate data analysis (7th ed.). Pearson New International Edition: Upper Saddle River.

Hamidi, H., \& Chavoshi, A. (2018). Analysis of the essential factors for the adoption of mobile learning in higher education: A case study of students of the University of Technology. Telematics and Informatics, 35(4), 1053-1070. https://doi.org/10.1016/j.tele.2017.09.016.

Haydon, T., Hawkins, R., Denune, H., Kimener, L., McCoy, D., \& Basham, J. (2012). A comparison of iPads and worksheets on math skills of high school students with emotional disturbance. Behavioral Disorders, 37(4), 232-243. https://doi.org/10.1177/019874291203700404.

Hayes, A. F. (2018). Introduction to mediation, moderation, and conditional process analysis: A regression-based approach (2nd ed.). New York: Guilford publications.

Hew, J. J., Lee, V. H., Ooi, K. B., \& Wei, J. (2015). What catalyses mobile apps usage intention: An empirical analysis. Industrial Management \& Data Systems, 115(7), 1269-1291. https://doi. org/10.1108/IMDS-01-2015-0028.

Horzum, M. B., Öztürk, E., Bektaş, M., Güngören, Ö. C., \& Çakır, Ö. (2014). Secondary school students tablet computer acceptance and readiness: A structural equation modelling. Education \& Science, 39(176), 81-93. https://doi.org/10.15390/EB.2014.3500.

Hung, C. M., Huang, I., \& Hwang, G. J. (2014). Effects of digital game-based learning on students' selfefficacy, motivation, anxiety, and achievements in learning mathematics. Journal of Computers in Education, 1(2-3), 151-166. https://doi.org/10.1007/s40692014-0008-8. 
Hwang, G. J., \& Chang, H. F. (2011). A formative assessment-based mobile learning approach to improving the learning attitudes and achievements of students. Computers \& Education, 56(4), 1023-1031. https://doi.org/10.1016/j.compedu.2010.12.002.

Hwang, G. J., \& Wu, P. H. (2014). Applications, impacts and trends of mobile technology enhanced learning: a review of 2008-2012 publications in selected SSCI journals. International Journal of Mobile Learning and Organisation, 8(2), 83-95. https://doi.org/10.1504/IJMLO.2014.062346.

Jairak, K., Praneetpolgrang, P., \& Mekhabunchakij, K. (2009). An acceptance of mobile learning for higher education students in Thailand. Special Issue of the International Journal of the Computer, the Internet and Management, 17(3), 1-8. Retrieved 21 January 2021 from http://www.cmruir.cmru. ac.th/bitstream/123456789/416/1/Full_Kallaya\%20Jairak.pdf.

Kim, H. J., \& Rha, J. Y. (2018). Predicting the drivers of the intention to use mobile learning in South Korea. International Journal of Interactive Mobile Technologies (iJIM), 12(1), 116-132. https://doi. org/10.3991/ijim.v12i1.7688.

Kline, R. B. (2011). Principles and practice of structural equation modeling (3rd ed.). New York: Guilford Press.

Koopman, J., Howe, M., Hollenbeck, J. R., \& Sin, H. P. (2015). Small sample mediation testing: Misplaced confidence in bootstrapped confidence intervals. Journal of Applied Psychology, 100(1), 194-202. https://doi.org/10.1037/a0036635.

Kyriakides, A. O., Meletiou-Mavrotheris, M., \& Prodromou, T. (2016). Mobile technologies in the service of students' learning of mathematics: The example of game application ALEX in the context of a primary school in Cyprus. Mathematics Education Research Journal, 28(1), 53-78. https://doi. org/10.1007/s13394-015-0163-x.

Lai, C. L., \& Hwang, G. J. (2014). Effects of mobile learning time on students' conception of collaboration, communication, complex problem-solving, meta-cognitive awareness and creativity. International Journal of Mobile Learning and Organisation, 8(3-4), 276-291. https://doi.org/10.1504/ IJMLO.2014.067029.

Larkin, K., \& Calder, N. (2016). Mathematics education and mobile technologies. Mathematics Education Research Journal, 28(1), 1-7. https://doi.org/10.1007/s13394-015-0167-6.

LawShe, C. H. (1975). A quantitative approach to content validity. Personnel Psychology, 28(4), 563575. https://doi.org/10.1111/j.1744-6570.1975.tb01393.x.

Limayem, M., Hirt, S. G., \& Cheung, C. M. (2007). How habit limits the predictive power of intention: The case of information systems continuance. MIS Quarterly, 31(4), 705-737. https://doi. org/10.2307/25148817.

Lin, P. C., Lu, H. K., \& Liu, S. C. (2013). Towards an education behavioral intention model for e learning systems: an extension of UTAUT. Journal of Theoretical \& Applied Information Technology, 47(3), 1120-1127. http://www.jatit.org/volumes/Vol47No3/37Vol47No3.pdf.

Martin, F., \& Ertzberger, J. (2013). Here and now mobile learning: An experimental study on the use of mobile technology. Computers \& Education, 68, 76-85. https://doi.org/10.1016/j.compe du.2013.04.021.

Moorthy, K., Yee, T. T., \& T'ing, L. C., \& Kumaran, V. V. . (2019). Habit and hedonic motivation are the strongest influences in mobile learning behaviours among higher education students in Malaysia. Australasian Journal of Educational Technology, 35(4), 174-191. https://doi.org/10.14742/ ajet.4432.

Nikolopoulou, K. (2018). Mobile learning usage and acceptance: perceptions of secondary school students. Journal of Computers in Education, 5(4), 499-519. https://doi.org/10.1007/s4069 2018-0127-8.

Nikolopoulou, K., Gialamas, V., \& Lavidas, K. (2020). Acceptance of mobile phone by university students for their studies: An investigation applying UTAUT2 model. Education and Information Technologies, 25(5), 4139-4155. https://doi.org/10.1007/s10639-020-10157-9.

Nikou, S. A., \& Economides, A. A. (2017). Mobile-based assessment: Investigating the factors that influence behavioral intention to use. Computers \& Education, 109, 56-73. https://doi.org/10.1016/j. compedu.2017.02.005.

Park, S. Y., Nam, M. W., \& Cha, S. B. (2012). University students' behavioral intention to use mobile learning: Evaluating the technology acceptance model. British Journal of Educational Technology, 43(4), 592-605. https://doi.org/10.1111/j.14678535.2011.01229.x.

Podsakoff, P. M., MacKenzie, S. B., Lee, J. Y., \& Podsakoff, N. P. (2003). Common method biases in behavioral research: a critical review of the literature and recommended remedies. Journal of Applied Psychology, 88(5), 879. https://doi.org/10.1037/00219010.88.5.879. 
Riconscente, M. M. (2013). Results from a controlled study of the iPad fractions game motion math. Games and Culture, 8(4), 186-214. https://doi.org/10.1177/1555412013496894.

Saedi, N., Taghizade, A., \& Hatami, J. (2018). The effect of mobile learning applications on students' high-level cognitive skills. Interdisciplinary Journal of Virtual Learning in Medical Sciences, 9(4), 1-6. https://doi.org/10.5812/ijvlms.69203.

Sollervall, H., Otero, N., Milrad, M., Johansson, D., \& Vogel, B. (2012). Outdoor activities for the learning of mathematics: Designing with mobile technologies for transitions across learning contexts. In 2012 IEEE seventh international conference on wireless, mobile and ubiquitous technology in education (pp. 33-40). IEEE.

Sultana, J. (2020). Determining the factors that affect the uses of Mobile Cloud Learning (MCL) platform Blackboard-a modification of the UTAUT model. Education and Information Technologies, 25(1), 223-238. https://doi.org/10.1007/s10639-019-099691.

Šumak, B., \& Šorgo, A. (2016). The acceptance and use of interactive whiteboards among teachers: Differences in UTAUT determinants between pre-and post adopters. Computers in Human Behavior, 64, 602-620. https://doi.org/10.1016/j.chb.2016.07.037.

Šumak, B., Polančič, G., \& Heričko, M. (2010). An empirical study of virtual learning environment adoption using UTAUT. In 2010 second international conference on mobile, hybrid, and on-line learning (pp. 17-22). IEEE.

Tabachnick, B. G., \& Fidell, L. S. (2013). Using multivariate statistics (6th ed.). New York: Pearson.

Tak, P., \& Panwar, S. (2017). Using UTAUT 2 model to predict mobile app-based shopping: Evidences from India. Journal of Indian Business Research, 9(3), 248-264. https://doi.org/10.1108/ JIBR-11-2016-0132.

Tamim, R. M., Borokhovski, E., Pickup, D., \& Bernard, R. M. (2015). Large-scale, government supported educational tablet initiatives. Commonwealth of Learning. Retrieved 03 August 2020 from http://oasis.col.org/handle/11599/809.

Wang, Y. S., Wu, M. C., \& Wang, H. Y. (2009). Investigating the determinants and age and gender differences in the acceptance of mobile learning. British Journal of Educational Technology, 40(1), 92-118. https://doi.org/10.1111/j.14678535.2007.00809.x.

Wijers, M., Jonker, V., \& Drijvers, P. (2010). MobileMath: exploring mathematics outside the classroom. ZDM, 42(7), 789-799. https://doi.org/10.1007/s11858-010-0276-3.

Wong, G. K. (2014). Engaging students using their own mobile devices for learning mathematics in classroom discourse: A case study in Hong Kong. International Journal of Mobile Learning and Organisation, 8(2), 143-165. https://doi.org/10.1504/IJMLO.2014.062352.

Wu, W. H., Wu, Y. C. J., Chen, C. Y., Kao, H. Y., Lin, C. H., \& Huang, S. H. (2012). Review of trends from mobile learning studies: A meta-analysis. Computers \& Education, 59(2), 817-827. https:// doi.org/10.1016/j.compedu.2012.03.016.

Venkatesh, V., Morris, M. G., Davis, G. B., \& Davis, F. D. (2003). User acceptance of information technology: Toward a unified view. MIS Quarterly, 27(3), 425-478. https://doi.org/10.2307/30036540.

Venkatesh, V., Thong, J. Y., \& Xu, X. (2012). Consumer acceptance and use of information technology: Extending the unified theory of acceptance and use of technology. MIS Quarterly, 36(1), 157-178. https://doi.org/10.2307/41410412.

Vinnik, V. (2017). User adoption of mobile applications: Extension of UTAUT2 model. Master thesis. Norwegian School of Economics.

Zhou, T., Lu, Y., \& Wang, B. (2010). Integrating TTF and UTAUT to explain mobile banking user adoption. Computers in Human Behavior, 26(4), 760-767. https://doi.org/10.1016/j.chb.2010.01.013.

Publisher's note Springer Nature remains neutral with regard to jurisdictional claims in published maps and institutional affiliations. 